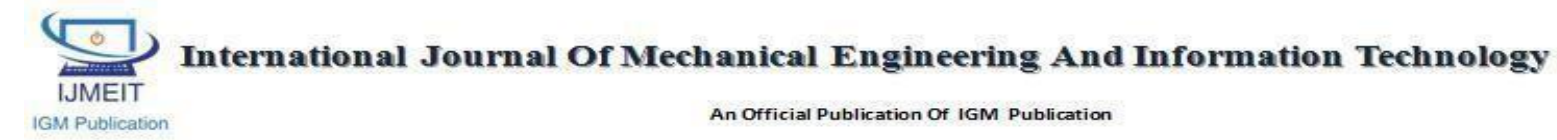

\title{
Comparative Performance Analysis of Conventional Solar Air Heater with Longitudinal Rectangular and Triangular Fins Attached Absorber
}

\author{
Authors \\ S.F. Hussain ${ }^{1}$, Dhruv Kumar ${ }^{2}$, Prabha Chand ${ }^{3}$, Abhishek Priyam ${ }^{4}$ \\ 1,2 Mechanical Engineering Department, NIMS University, Jaipur, 303121, India \\ ${ }^{3,4}$ Mechanical Engineering Department, National Institute of Technology, Jamshedpur, 831014, India
}

\begin{abstract}
: -
In this paper, the performance analysis of solar air heater with triangular longitudinal fins has been analyzed theoretically. The flowing channel is formed by two diagonally positioned triangular fins attached on the absorber plate with bottom side thermally insulated and the top surface of absorber plate subjected to unvarying heat flux. The expression for collector efficiency factor of such collector has been established. Effects of mass flow rates and varying solar flux on the thermal performance have been presented and the results are compared with plain solar air heater and rectangular finned solar air heater. Various factors versus mass flow rate and solar flux graphs were plotted. The mathematical model provides reasonable indication of the performance of triangular fin solar air heater and it can be useful in designing such types of solar airheater.
\end{abstract}

Keywords: - Solar air heater, Triangular finned, Plain solar air heater.

\section{INTRODUCTION: -}

Solar energy route has been acknowledged as one of the favorable unorthodox energy sources for the future. In any gathering device, the principle usually followed is to expose a dark surface to solar radiation so that the radiation is absorbed and part of the captivated radiation is then shifted to a fluid like air or water. The heat transfer coefficient value between the absorber plate and the air is low which results in lower efficiency. For this reason, longitudinal fins are attached in the air flow passage. There are numerous outline parameters e.g. number of glass cover, emissivity of absorber plate, collector length, collector duct depth or distance between absorber and bottom plates in conventional solar air heater, and the ratio of collector length to collector width i.e. collector aspect ratio, etc., affecting the solar air heater efficiency.

E Morse was the first American person who designed and produced solar air heater in 1881.
In 1940s, major development was taken in the field of solar collectors by another American KMiller. Elenbass had done extensive work on channels and parallel plates on experimental and semi-empirical basis.

Starner and Mcmanus presented free convection data for four rectangular arrays in three positions including vertical position for the fin base. Similarly experimental work for vertical fin arrays is carried out. Due to lower thermo physical properties of air, extended surfaces like fins and baffles, roughened absorber and packed beds are used to enhance the heat transfer rate without the increase in size (Krieder and Krieth, 1978).

Thermal performance of double flow solar air heaters by using aluminum cans first in zigzag way then in order and lastly without cans was investigated experimentally for different mass flow rates (Ozgen et al., 2009). 


\section{Nomenclature}

$C_{p}=$ Specific heat $(\mathrm{kJ} / \mathrm{kg}-\mathrm{K})$.

$d_{e}=$ Equivalent diameter $(\mathrm{m})$.

$h_{e}=$ Effective heat transfer coefficient $\left(\mathrm{W} / \mathrm{m}^{2}-\mathrm{K}\right)$.

$h_{f b}=$ Heat transfer coefficient between bottom plateand air stream $\left(\mathrm{W} / \mathrm{m}^{2}-\mathrm{K}\right)$.

$h_{f f}=$ Heat transfer coefficient between fin surface and air stream $\left(\mathrm{W} / \mathrm{m}^{2}-\mathrm{K}\right)$.

$h_{f p}=$ Heat transfer coefficient between absorber plateand air stream $\left(\mathrm{W} / \mathrm{m}^{2}-\mathrm{K}\right)$.

$h_{r}=$ Radiative heat transfer coefficient $\left(\mathrm{W} / \mathrm{m}^{2}-\mathrm{K}\right)$.

$h_{w}=$ wind heat transfer coefficient $\left(\mathrm{W} / \mathrm{m}^{2}-\mathrm{K}\right)$.

$I=$ Flux at different depth inside solar pond $\left(\mathrm{W} / \mathrm{m}^{2}\right)$.

$k=$ Thermal conductivity $(\mathrm{W} / \mathrm{m}-\mathrm{K})$.

$k_{i}=$ Thermal conductivity of insulation $(\mathrm{W} / \mathrm{m}-\mathrm{K})$.

$L=$ Spacing between the absorber plate and bottomplate (m).

$L_{1}=$ Length of absorber plate $(\mathrm{m})$.

$L_{2}=$ Width of absorber plate (m).

$L_{3}=$ Height of the collector casing $(\mathrm{m})$.

$L_{f}=$ Fin height $(\mathrm{m})$.

$q_{u}=$ Useful heat gain rate $(\mathrm{W})$.

$S=$ Incident solar flux absorbed in the absorber plate $\left(\mathrm{W} / \mathrm{m}^{2}\right)$.

$T_{a}=$ Ambient temperature (K).

$T_{i}=$ Initial temperature $(\mathrm{K})$.

$T_{f m}=$ Local fluid temperature (K).

$T_{p m}=$ Mean absorber surface temperature $(\mathrm{K})$.

$T_{o}=$ Air outlet temperature (K).

$U_{b}=$ Bottom loss coefficient $\left(\mathrm{W} / \mathrm{m}^{2}-\mathrm{K}\right)$.

Investigation was also carried on three different solar air heaters, without fins and double glass cover then double glass cover with fins and finally single glass cover with fins (Alta et al., 2010). The energy and exergy analysis of these solar air heaters showed that the one with a double glass cover with fins was the most effective and the highest difference between the inlet and the outlet temperatures was achieved.

El-Khawajah et al. investigated on a double pass solar air heater using two, four and six transverse fins and wire mesh as an absorber (El-Khawajah
$U_{S}=$ Side loss coefficient $\left(\mathrm{W} / \mathrm{m}^{2}-\mathrm{K}\right)$

$U_{l}=$ Overall loss coefficient $\left(\mathrm{W} / \mathrm{m}^{2}-\mathrm{K}\right)$.

$U_{t}=$ Top loss coefficient $\left(\mathrm{W} / \mathrm{m}^{2}-\mathrm{K}\right)$.

$V_{\infty}=$ Free stream wind speed $(\mathrm{m} / \mathrm{s})$.

$v=$ Kinematic viscosity $\left(\mathrm{m}^{2} / \mathrm{s}\right)$.

$V=$ Average air velocity $(\mathrm{m} / \mathrm{s})$.

$W=$ Fin spacing $(\mathrm{m})$.

$\Delta_{p}=$ pressure drop $\left(\mathrm{N} / \mathrm{m}^{2}\right)$.

Dimensionless numbers

$f=$ friction factor.

$F^{\prime}=$ Collector efficiency factor.

$F_{R}=$ Collector heat removal factor.

$M=$ Number of glass cover.

$N u=$ Nusselt number.

$p_{r}=$ Prandtl number.

$R_{e}=$ Reynolds number.

Greek letters

$\beta=$ Slope or tilt.

$\delta_{b}=$ Thickness of bottom insulation (m).

$\delta_{f}=$ Thickness of fin (m).

$\delta_{s}=$ Thickness of side insulation (m).

$\varepsilon_{c}=$ Emissivity of cove.

$\varepsilon_{b}=$ Emissivity of bottom plate.

$\varepsilon_{p}=$ Emissivity of absorber plate.

$\varphi_{f}=$ Fin Effectiveness.

$\eta_{i}=$ Instantaneous collection efficiency.

$\dot{\mathrm{m}}=$ Mass flow rate $(\mathrm{kg} / \mathrm{s})$.

$\mu=$ Viscosity $\left(\mathrm{N}-\mathrm{s} / \mathrm{m}^{2}\right)$.

$\rho=$ Density $\left(\mathrm{kg} / \mathrm{m}^{3}\right)$.

$\left(\tau_{a}\right)_{a v}=$ Transmissivity-absorptivity product for beamradiation.

et al., 2011). Results showed that the efficiency enhanced with the increase in number of fins.

An investigation on double pass solar air heater with finned and v-corrugated plate was done to determine the thermal performance (El-Sebaii et al., 2011).

Another experimental investigation was done to analyze performance of five types of solar air collectors viz. corrugated, reverse corrugated, trapeze, reverse trapeze and base air heater (Benli, 2013). Performance of the single pass air heater with fins and baffles attached to the absorber plate was evaluated by Mohammadi and Sabzpooshani (2013). 
Theoretical and experimental studies were done on Choudharyand Garg (1991) five types of configuration for their design analysis. Performance of flat plate, v-corrugated and finned air collectors were examined over a wide range of operating and design conditions (Karim and Hawlader, 2006). Performance of finned type solar air heater shows better efficiency with fins (Garg et al., 1989). Double pass finned, double glazing and the conventional solar air heater were analyzed and the one with double pass fins was observed to be the most efficient (Bhandari and Singh, 2012).

Thermal performance of a single pass solar air heater with and without fins was investigated on different mass flow rates. In many studies, (Junqi et al., 2007; Jang and Chen, 1997; Junqi et al., 2010; Sheik Ismail et al., 2009; Tsai et al., 1999; Tao et al., 2007; Wongwises and Chokeman, 2005; Ramgadia and Saha, 2012) wavy fins were tested in heat exchangers experimentally as well as theoretically or both.

Sheven et al. Classified various air heating collector designs under six categories according to the type of absorbing surface.

Further variations may be defined by the performance improvement techniques employed and by the air flow path.

Theoretical and experimental studies on the corrugated sheet type of solar air collectors were first conducted by Buelow.

The cost of air heating by a solar collector is dominated by the collector material cost and air pumping cost. Charters examined the optimization of the aspect ratio of the rectangular flow passage from the view point of minimizing the cost for a fixed pumping power. Hollands and Scheven studied the effect of the dimensions of the rectangular and triangular air flow passages on the coefficient of forced convective heat transfer from absorber to flowing air in plate type air heating collectors. The study carried out by Choudhury and Garg, suggestions citing specific examples have been made on the design selection criteria at a predetermined pressure drop required to obtain design features with moderately high efficiency. Hamdan and Jubram have evaluated the costeffectiveness of bare, covered-and finned-plate air heaters for the Jordian climate.

\section{THEORETICAL ANALYSIS: -}

The addition of continuous longitudinal fins to the bottom sides of the absorber plate improves the heat transfer. This is desirable because it increases the efficiency. We now analyze such a heater in which fins of height $L_{f}$ and thickness $\delta_{f}$ are spaced at a distance $\mathrm{W}$ Centre-to-Centre apart. The distance between the absorber plate and bottom plate is L. consequently the clearance between the fins and the bottom plate is $\left(\mathrm{L}-L_{f}\right)$. Considering a slice of width $\mathrm{W}$ and thickness $\mathrm{dx}$ at a distance $\mathrm{x}$ from the inlet, we write down the energy balance for the absorber plate, the bottom plate and the air flowing in between.

The heater has an absorber plate of length $L_{1}$ and width $L_{2}$. The air flow in parallel plate passage below the absorber plate.

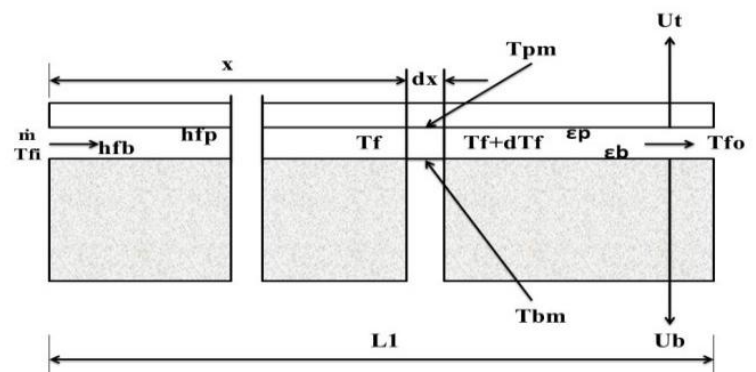

Fig. 1: Analysis of conventional solar air heater. The analysis is due to whillier and proceeds along lines identical to those adopted for the liquid flat plate collector for the calculation of $(\tau \alpha)_{b},(\tau \alpha)_{d}$, $U_{t}$ and $U_{b}$. Considering a slice of width $L_{2}$ and thickness $\mathrm{dx}$ at a distance $\mathrm{x}$ from the inlet, we write down energy balance for the absorber plate, the plate below it, and the air flowing in between. We assume that

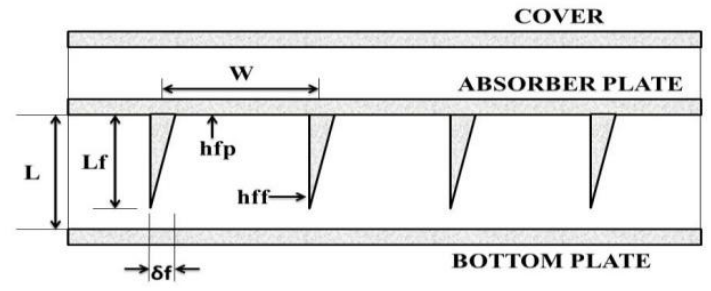

Fig. 2: Conventional air heater with triangular fins. 


\section{IJMEIT// Vol.04 Issue 08//August//Page No:1693-1701//ISSN-2348-196x}

The bulk mean temperature of the air changes from $T_{f}$ to $\left(T_{f}+d T_{f}\right)$ as it flows through the distance $\mathrm{dx}$.

The air mass flow rate is $\dot{m}$.

The mean temperature of the absorber plate and the plate below are $T_{p m}$ and $T_{b m}$ respectively and their variation may be neglected.

Side's losses can be neglected.

The following equations are obtained:

ABSORBER PLATE: -

$\mathrm{SW} \mathrm{dx}=U_{t} \mathrm{~W} \mathrm{dx}\left(T_{p m}-T_{a}\right)+h_{f p} \mathrm{~W} \mathrm{dx}\left(T_{p m}-T_{f}\right)$ $+2 L_{f} \mathrm{dx} \varphi \mathrm{f} h_{f f}\left(T_{p m}-T_{f}\right)+h_{r} \mathrm{~W} \mathrm{dx}\left(T_{p m}-T_{b m}\right)$

BOTTOM PLATE: -

$h_{r} \mathrm{~W} \mathrm{dx}\left(T_{p m}-T_{b m}\right)=h_{f b} \mathrm{~W} \mathrm{dx}\left(T_{b m}-T_{f}\right)+$ $U_{b} \mathrm{~W} \mathrm{dx}\left(T_{b m}-T_{a}\right)$

AIR STREAM: -

$$
\begin{array}{r}
\frac{W}{L_{2}} \dot{\mathrm{m}} C_{p} d T_{f}=h_{f p} \mathrm{~W} \mathrm{dx}\left(T_{p m}-T_{f}\right)+ \\
2 L_{f} \mathrm{dx} \varphi \mathrm{f} h_{f f}\left(T_{p m}-T_{f}\right)+h_{f b} \mathrm{~W} \mathrm{dx}\left(T_{b m}-T_{f}\right)----
\end{array}
$$

While writing the energy balance equation, we distinguish between $h_{f p}$, the convective heat transfercoefficient for the absorber plate and the air, and $h_{f b}$, the convective heat transfercoefficient for the bottom plate and the air. However the dissimilarity is usually not made in the correlation available for calculating the convective heat transfer coefficients. Thus while using these correlations, we have to assume $h_{f p}=h_{f b}$.

We introduce an equivalent radiative heat transfer coefficient $h_{r}$ defined in the case by

$\frac{\sigma L_{2} d x}{\left(\frac{1}{\varepsilon_{p}}+\frac{1}{\varepsilon_{b}}-1\right)}\left(T_{p m}^{4}-T_{b m}^{4}\right)=\mathrm{h}_{\mathrm{r}}\left(T_{p m}-T_{b m}\right)---$

For small values of the temperature difference $\left(T_{p m}-T_{b m}\right)$, it is readily shown that the expression $\left(T_{p m}^{4}-T_{b m}^{4}\right)$ can be approximated by the expression $4 \mathrm{~T}^{3} \mathrm{av}\left(T_{p m}-T_{b m}\right)$ where $T_{a v}=$ $\left(T_{p m}+T_{b m}\right) / 2$. Then

$h_{r}=\frac{4 \sigma T_{a v}^{3}}{\left(\frac{1}{\varepsilon_{p}}+\frac{1}{\varepsilon_{b}}-1\right)}$

Further, it is assumed for purposes of simplification that the bottom loss coefficient $U_{b}$ is much smaller in magnitude than the top loss coefficient $U_{t}$. Consequently the bottom loss term can be deleted from Eq. (1.2) and clubbed with the top loss term in Eq. (1.1). Equation (1.1) and (1.3) thus reduced to

$$
\begin{aligned}
& \mathrm{S}=U_{l}\left(T_{p m}-T_{a}\right)+h_{f p}\left(1+\frac{2 L_{f} \varphi \mathrm{f} h_{f f}}{W h_{f p}}\right)\left(T_{p m}-T_{f}\right) \\
& +h_{r}\left(T_{p m}-T_{b m}\right) \text {-------- }(1.5) \\
& h_{r}\left(T_{p m}-T_{b m}\right)=h_{f b}\left(T_{b m}-T_{f}\right) \text {------ }(1.6) \\
& \frac{\dot{\mathrm{m}} C_{p} d T_{f}}{L_{2} d x}=h_{f p}\left(1+\frac{2 L_{f} \varphi \mathrm{f} h_{f f}}{W h_{f p}}\right)\left(T_{p m}-T_{f}\right)+h_{f b} \\
& \left(T_{b m}-T_{f}\right)--(1.7)
\end{aligned}
$$

From Equation (1.6), we get

$T_{b m}=\frac{h_{r} T_{p m}+h_{f b} T_{f}}{h_{f b}+h_{r}}$

Substituting this expression into equation (1.5), we have

$T_{p m}=\frac{S+U_{l} T_{a}+h_{e} T_{f}}{U_{l}+h_{e}}$

$h_{e}=h_{f p}\left(1+\frac{2 L_{f} \varphi_{f} h_{f f}}{W h_{f p}}\right)+\frac{h_{r} h_{f b}}{h_{r}+h_{f b}}$

is an effective heat transfer coefficient between the absorber plate with fins and air stream.

From equation (1.5), (1.6) and (1.7), we have

$\frac{\dot{\mathrm{m}} C_{p}}{L_{2}} \frac{d T_{f}}{d x}=\mathrm{S}-U_{l}\left(T_{p m}-T_{a}\right)$

Substituting the expression for $\left(T_{p m}-T_{a}\right)$ in Eq.

(1.11), we get the differential equation

$\frac{\dot{\mathrm{m}} C_{p}}{L_{2}} \frac{d T_{f}}{d x}=\frac{1}{\left(1+\frac{U_{l}}{h_{e}}\right)}-\left\{S-U_{l}\left(T_{f}-T_{a}\right)\right\}-$

In an comparable manner to the liquid flat plate collector, we now express a collector efficiency factor F' given by

$F^{\prime}=\left(1+\frac{U_{l}}{h_{e}}\right)^{-1}$

Equation (1.12) thus becomes

$\frac{\dot{\mathrm{m}} C_{p}}{L_{2}} \frac{d T_{f}}{d x}=F^{\prime}\left\{\mathrm{S}-U_{l}\left(T_{f}-T_{a}\right)\right\}$

The solution now proceeds along identical lines and we obtain the fluid temperature distribution

$\frac{\left(\frac{S}{U_{l}}+T_{a}\right)-\mathrm{Tf}}{\left(\frac{S}{U_{l}}+T_{a}\right)-T_{f_{i}}}=\exp \left(-\frac{L_{2} F^{\prime} U_{l} x}{\mathrm{~m} C_{p}}\right)$

Subtracting both sides of Equation (1.15) from unity,

$q_{u}=\mathrm{F}_{\mathrm{R}} \mathrm{A}_{\mathrm{P}}\left\{\mathrm{S}-U_{l}\left(T_{f i}-T_{a}\right)\right\}$

Where, 
$\mathrm{F}_{\mathrm{R}}=\frac{\dot{\mathrm{m}} C_{p}}{U_{l}}\left[1-\exp { }^{\left(-\frac{L_{2} F^{\prime} U_{l} x}{\dot{\mathrm{m}} C_{p}}\right)}\right]$

The term $F_{R}$ is called collector heat removal factor. It is a measure of the thermal resistance encountered by the absorbed solar radiation in reaching the collector fluid.

Whillier gave an expression for the collector efficiency factor of a finned air heater by neglecting the radiative heat transfer but by considering an absorber plate effectiveness $\varphi_{f}$. The two expressions for F' can be shown to be identical if $h_{r}$ is made equal to zero in one and $\varphi_{f}$ is made equal to unity in the other.

To calculate the performance of a finned solar air heater, correlations are required for determining the values of the convective heat transfer coefficient and the pressure drop. Thombre and Sukhatme have suggested an appropriate correlation for the heat transfer coefficient. Their data shows that, if the clearance-to-spacing ratio $\left(\mathrm{L}-L_{f}\right) /\left(\mathrm{W}-\delta_{f}\right)$ is less than one or the spacing-tofin height ratio $\left(\mathrm{W}-\delta_{f}\right) / L_{f}$ is greater than one then Dittus-Boelter equation is applicable. The nusselt number is then given by

$\mathrm{Nu}=0.023 \operatorname{Re}^{0.8} \operatorname{Pr}^{0.4}$

Where the characteristic dimension used in the definition of $\mathrm{Nu}$ and $\mathrm{Re}$ is the equivalent diameter $\mathrm{d}_{\mathrm{e}}$ given by

$d_{e}=\frac{4 \times \text { Cross }- \text { sectional area of the fin channel }}{\text { Wetted perimeter of a fin channel }}$

$d_{e}=\frac{4\left(W \times L-\frac{1}{2}\left(L_{f} \times \delta_{f}\right)\right.}{2\left(W+L+\left(W-\delta_{f}\right)+\sqrt{\left(\delta_{f}\right)^{2}+\left(L_{f}\right)^{2}}+\left(L-L_{f}\right)\right)}$

Properties are evaluated at the arithmetic mean of the air inlet and outlet temperature, and the values of $h_{f p}, h_{f f}$ and $h_{f b}$ are taken to be equal.

The following correlation is developed for calculating the pressure drop

$\mathrm{f}=\mathrm{M} \mathrm{Re}^{-\mathrm{m}}$

Where,

$\mathrm{M}=0.040\left[2.058-\left\{\left(\mathrm{L}-L_{f}\right) / L_{f}\right\}^{0.313}\right]$

for

$\operatorname{Re}<15000$

$\mathrm{M}=0.033\left[1.394-\left\{\left(\mathrm{L}-L_{f}\right) / L_{f}\right\}^{0.408}\right]$

for

$\operatorname{Re}>15000$
$\mathrm{m}=0.075\left[3.40-\left\{\left(\mathrm{L}-L_{f}\right) / L_{f}\right\}^{0.711}\right] \quad$ for

$\operatorname{Re}<15000$

$\mathrm{m}=0.138\left[1.435-\left\{\left(\mathrm{L}-L_{f}\right) / L_{f}\right\}^{0.773}\right]$

for

$\operatorname{Re}>15000$

\section{Top loss coefficient: -}

The top loss coefficient $U_{t}$ is assessed by considering convection and re-radiation losses from the absorber plate in the upward direction. For iterativecalculation purpose, it is assumed that the transparent covers and the absorber plate organize a system of inestimable parallel surfaces and that the flow of heat is one dimensional and steady. It is further assumed that the temperature drop across the thickness of the covers is insignificant and that the interface between the received solar radiation absorbed by the covers and the outgoing losses may be neglected. The outgoing re-radiation is of large wavelengths and the transparent cover is assumed to be opaque. Based on calculation for a large number of cases covering the entire range of conditions customarily expected for flat plate collector, Klein has developed the following appropriate empirical equation for calculating the top loss coefficient.

$$
\begin{array}{r}
U_{t}=\left[\frac{M}{\left(\frac{C}{T_{p m}}\right)\left(\frac{T_{p m}-T_{a}}{M+f}\right)^{0.33}}+\frac{1}{h_{w}}\right]^{-1} \\
+\left[\frac{\sigma\left(T_{p m}^{2}+T_{a}^{2}\right)\left(T_{p m}+T_{a}\right)}{\frac{1}{\varepsilon_{p+0.05 M\left(1-\varepsilon_{p}\right)}}+\frac{(2 M+f-1)}{\varepsilon_{c}}-M}\right]
\end{array}
$$

Where

$$
\begin{aligned}
& \mathrm{f}=\left(1-0.04 h_{w}+0.0005 h_{w}^{2}\right)(1+0.091 \mathrm{M}) \\
& \mathrm{C}=365.9\left(1-0.00883 \beta+0.0001298 \beta^{2}\right) \\
& \mathrm{M}=\text { number of glass covers }
\end{aligned}
$$

$T_{p m}$ and $T_{a}$ are expressed in $\mathrm{K}, h_{w}$ in $\mathrm{W} / \mathrm{m}^{2}-\mathrm{K}$ and $\beta$ in degrees. The value of $U_{t}$ is obtained in $\mathrm{W} / \mathrm{m}^{2}-\mathrm{K}$. The range over which the equation has been developed are as follows:

$320 \leq T_{p m} \leq 420 \mathrm{~K}$.

$260 \leq T_{a} \leq 310 \mathrm{~K}$.

$0.1 \leq \varepsilon_{p} \leq 0.95$. 
$0 \leq V_{\infty} \leq 10 \mathrm{~m} / \mathrm{s}$.

$1 \leq \mathrm{M} \leq 3$.

$0 \leq \beta \leq 90^{\circ}$.

Heat transfer coefficient at the top cover:

The convective heat transfer coefficient $\left(h_{w}\right)$ at the top cover has been premeditated by the following empirical correlation suggested by McAdams,

$$
h_{w}=5.7+3.8 V_{\infty}
$$

in which $h_{w}$ is in $\mathrm{W} / \mathrm{m}^{2}-\mathrm{K}$ and $V_{\infty}$ is the wind speed in $\mathrm{m} / \mathrm{s}$.

\section{Bottom loss coefficient: -}

The bottom loss coefficient $U_{b}$ is assessed by considering conduction and convection losses from the absorber plate in the downward direction through the bottom of the collector. It will be assumed that the flow of heat is one dimensional and steady. Thus, for calculating bottom loss coefficient, we have

$$
U_{b}=\frac{k_{i}}{\delta_{b}}
$$

Where $\quad k_{i}=$ Thermal conductivity of the insulation,

$$
\delta_{b}=\text { Thickness of theinsulation. }
$$

\section{Side loss coefficient: -}

It is assumed that the conduction resistant dictates and that the flow of heat is one dimensional and steady. The one dimensional guesstimate can be justified on the grounds that the side loss coefficient is always much smaller than the top loss coefficient. If the dimension of the absorber plate are $L_{1} \times L_{2}$ and the height of the collector casing is $L_{3}$, then the area across which the heat flows sideways is $2\left(L_{1}+L_{2}\right) L_{3}$. The temperature drop across which the heat flows occurs diverges from $\left(T_{p m}-T_{a}\right)$ at the absorber plate level to zero both at the top and bottom. Presumptuous, therefore, that the average temperature drop across the side insulation is $\left(T_{p m}-T_{a}\right) / 2$ and that the thickness of the insulation is $\delta_{s}$, we have

$$
\mathrm{U}_{\mathrm{s}}=\frac{\left(L_{1}+L_{2}\right) \mathrm{L}_{3} k_{i}}{L_{1} L_{2} \delta_{s}}
$$

\section{RESULT AND DISCUSSION: -}

The thermal performance of solar air heater depends on intensity of solar radiation, design parameters such as thickness of insulation, number of glass cover, glazing and absorber materials, orientation of absorber and operating conditions, etc. The variation in different parameters at constant solar flux intensity and increasing mass flow rate in all the three types of modification in absorber plate was shown in fig. 9 to fig. 16 .

The following parameters are used for numerical calculation:

$\mathbf{L}_{\mathbf{1}}=2 \mathrm{~m}, \quad \mathbf{L}_{\mathbf{2}}=1 \quad \mathrm{~m}, \quad \mathbf{L}_{\mathbf{3}}=0.1 \mathrm{~m}, \quad \boldsymbol{L}=0.2 \mathrm{~m}$, $\dot{\mathrm{m}}=0.01389,0.02778,0.04167,0.05556 \mathrm{Kg} / \mathrm{s}$, $\boldsymbol{T}_{\boldsymbol{i}}=310 \mathrm{~K}, \mathbf{T}_{\boldsymbol{a}}=300 \mathrm{~K}, \mathrm{~S}=600,700,800,900$ $\mathrm{W} / \mathrm{m}^{2}, \quad(\boldsymbol{\tau} \boldsymbol{\alpha})_{\boldsymbol{a} v}=0.85, \quad \boldsymbol{\varepsilon}_{\boldsymbol{p}}=0.28, \quad \boldsymbol{\varepsilon}_{\boldsymbol{b}}=0.28, \quad \mathrm{M}=1$, $\boldsymbol{V}_{\infty}=2 \mathrm{~m} / \mathrm{s}, \beta=0^{\circ}$

$\boldsymbol{\delta}_{\boldsymbol{b}}=0.08 \mathrm{~m}, \boldsymbol{\delta}_{\boldsymbol{s}}=0.05 \mathrm{~m}, \boldsymbol{\varepsilon}_{\boldsymbol{c}}=0.88$. The numerous performance curves have been plotted.

The variation of different factors of solar air heater due to all the three types of modification in absorber plate are shown in fig.4, fig.5, fig.6, fig. 7 , fig.8 and fig. 9.

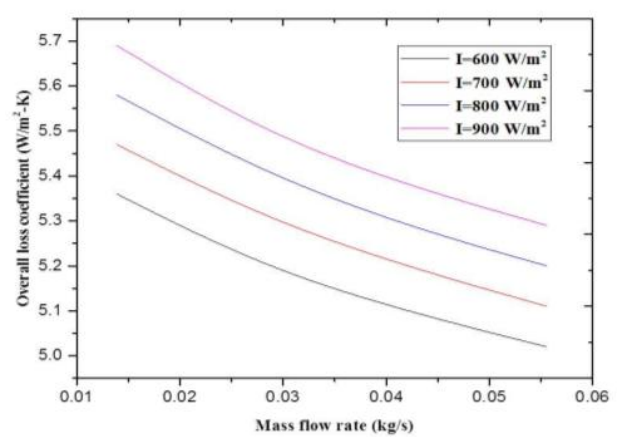

Fig. 3 Overall loss coefficient as a function of mass flow rate for simple solar air heater.

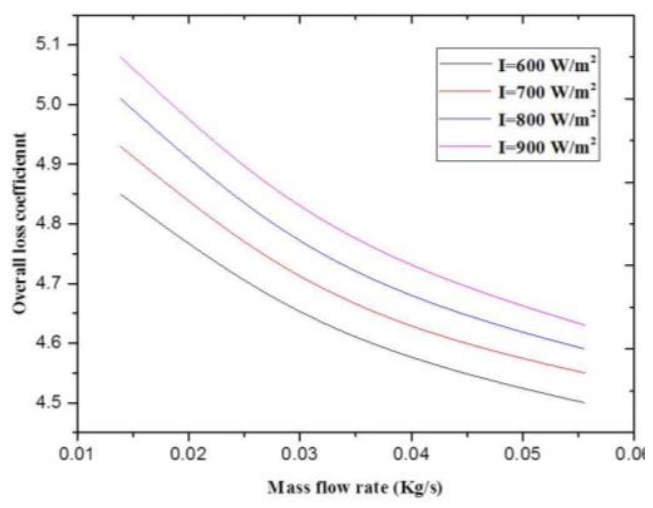

Fig. 4 Overall loss coefficient as a function of mass flow rate. 
Comparison of Fig. 3 and Fig. 4 show the total loss coefficient as a function of mass flow rate for various values of solar flux for simple and triangular finned solar air heater. The total loss coefficient for triangular finned solar air heater decreases with the increase in mass flow rate. Also, decrease in solar flux intensity increases total loss coefficient. The minimum loss coefficient of $4.5 \mathrm{~W} / \mathrm{m}^{2}-\mathrm{K}$ has been found for the solar flux of $600 \mathrm{~W} / \mathrm{m}^{2}$. This occurs due to, the mean plate temperature decreases for the defined range of mass flow. This in turn results in decrease in top loss coefficient.

It can be observed that a detraction of 1.14 times has been found for triangular fin solar air heater for higher mass flow rate of $0.05556 \mathrm{~kg} / \mathrm{s}$ as compared to plane solar air heater.

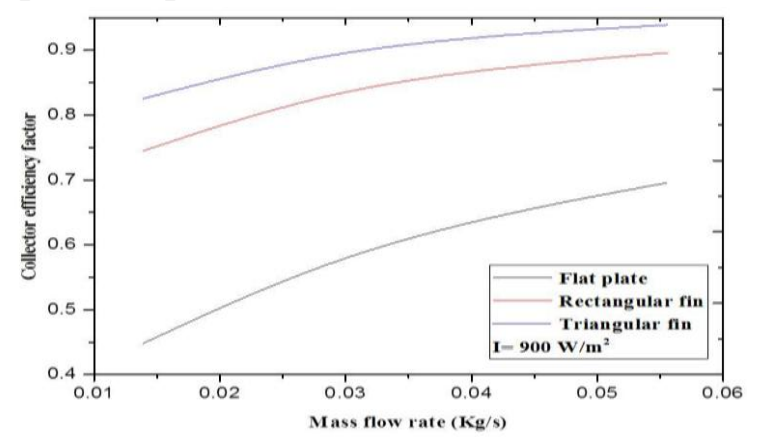

Fig. 5 Collector efficiency factor as a function of mass flow rate for triangular fin solar air heater.

Fig. 5 indicates the collector efficiency factor as a function of mass flow rate for different types of absorber plate. The maximum collector efficiency factor was calculated theoretically in case of simple, rectangular finned and Triangular finned solar air heater. As the mass flow rate increases at constant solar flux intensity, there is an increase in collector efficiency factor. Also collector efficiency is increased by decrease in overall loss coefficient as the mass flow rate increases simultaneously. It can be observed that an enhancement of 1.39 times has been found for triangular fin solar air heater for higher mass flow rate of $0.05556 \mathrm{~kg} / \mathrm{s}$ and lower solar flux of 600 $\mathrm{W} / \mathrm{m}^{2}$ as compared to plane solar air heater.

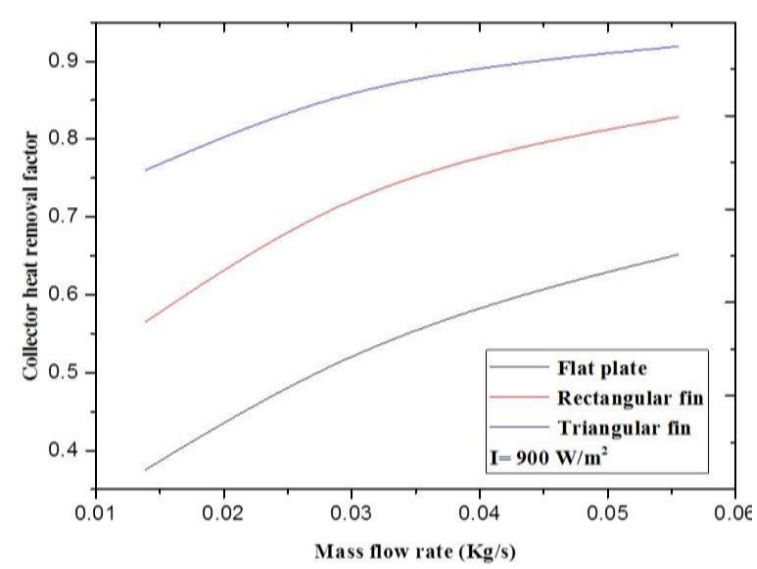

Fig. 6 Collector heat removal factor as a function of mass flow rate.

The variation of collector heat removal factor with mass flow rate for different absorber plate is plotted in Fig. 6. When mass flow rate increases, collector heat removal factor also increases. It is inversely proportional to the overall loss coefficient i.e. as the overall loss coefficient increases, collector heat removal factor decreases. It can be observed that an enhancement of 1.39 times has been found for triangular fins solar air heater for higher mass flow rate of $0.05556 \mathrm{~kg} / \mathrm{s}$ and lower solar flux of $600 \mathrm{~W} / \mathrm{m}^{2}$ when compared to plane solar air heater.

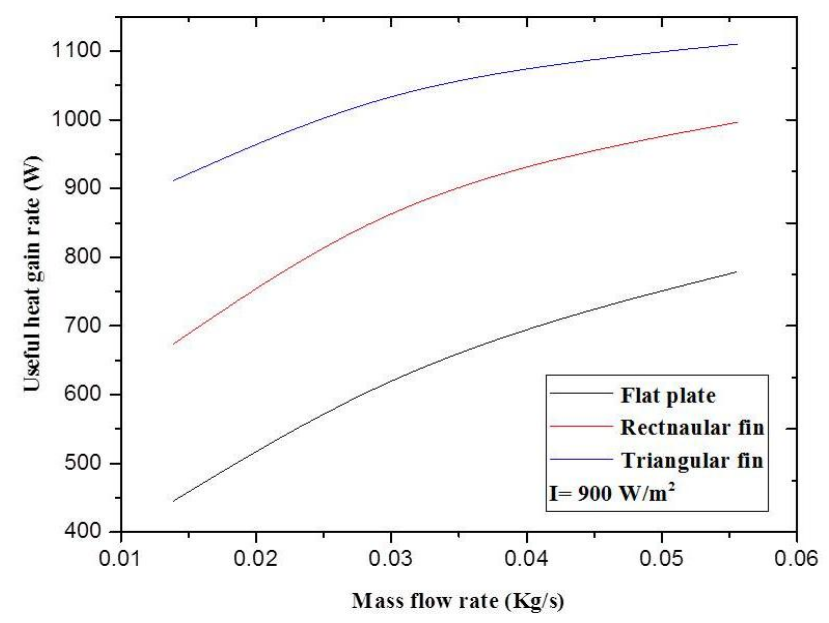

Fig. 7 Useful heat gain rate as a function of mass flow rate.

In this section, the effect of useful heat gain rate as a function of mass flow rate for different types of absorber plate is shown in Fig. 7. As the mass flow rate increases at constant solar flux intensity, the useful heat gain rate increases correspondingly. With the increase in mass flow rate there is a decrease in overall loss coefficient which increase the useful heat gain rate. It is seen 


\section{IJMEIT// Vol.04 Issue 08//August//Page No:1693-1701//ISSN-2348-196x}

that an increase of $29.83 \%$ in useful heat gain rate has been found for triangular fins solar air heater for higher mass flow rate of $0.05556 \mathrm{~kg} / \mathrm{s}$ as compared to plane solar air heater.

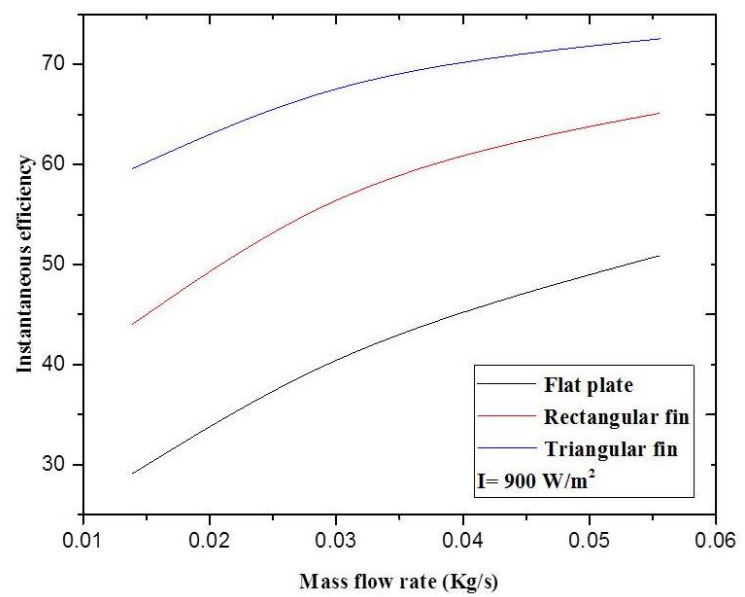

Fig. 8 Instantaneous efficiency as a function of mass flow rate.

Fig. 8 analyzes the behavior of instantaneous efficiency as a function of mass flow rate. Instantaneous efficiency directly depends upon the useful heat gain rate acquired at constant solar flux intensity. Also when the mass flow rate increases at constant solar flux intensity, there is an increase in efficiency. It can be observed that an increment of $29.84 \%$ in instantaneous efficiency is been found with triangular fins solar air heater for higher mass flow rate of 0.05556 $\mathrm{kg} / \mathrm{s}$ when compared to plane solar air heater.

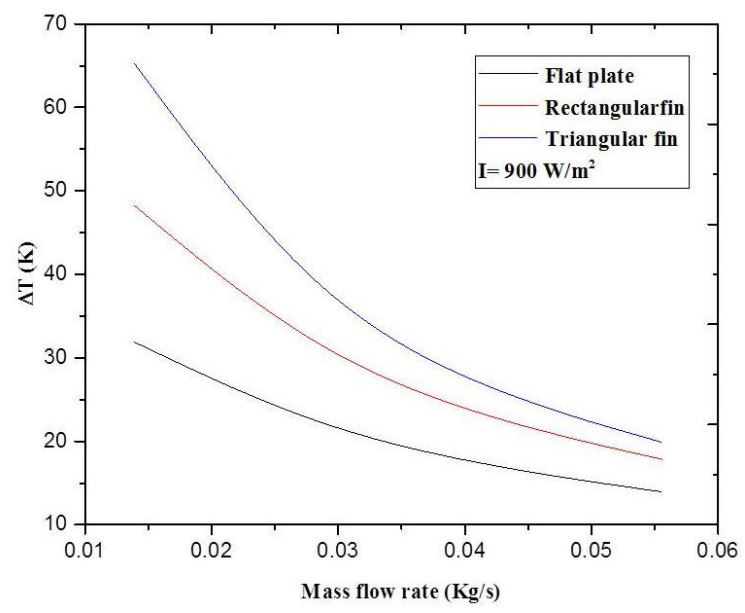

Fig. 9 Temperature difference as a function of mass flow rate.

Fig. 9 reveals the temperature difference as a function of mass flow rate for different absorber plate. As the air enters into the channel and comes out after heating, the difference in temperature was assessed and it is observed that $8.89 \%$ of temperature increase has been found for triangular fins solar air heater for lower mass flow rate of $0.013889 \mathrm{~kg} / \mathrm{s}$ when compared to plain solar air heater. It also depends upon the specific heat of air. As the plate temperature increases the specific heat of air will also increases.

Fig. 10 shows the pressure drop as a function of mass flow rate for simple, rectangular finned and triangular finned solar air heater. It is observed that, as the mass flow rate increases at constant solar flux intensity, the pressure drop increases correspondingly. Pressure drop directly depends upon the friction coefficient factor.

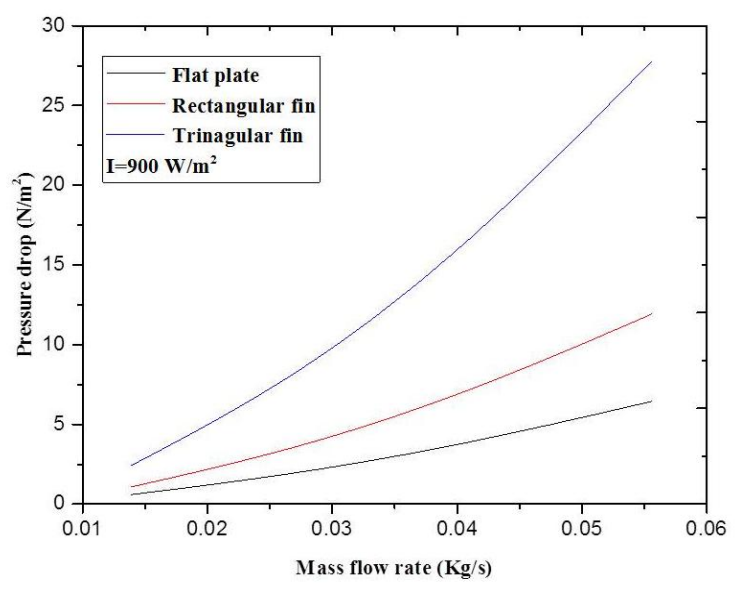

Fig. 10 Pressure drop as a function of mass flow rate.

Increase in air flow rate results in increase in turbulence and hence increased friction coefficient and hence pressure loss increases. The maximum enhancement in pressure drop has been found in order of 4.31 times with triangular fins solar air heater of higher mass flow rate of $0.05556 \mathrm{~kg} / \mathrm{s}$ when compared to plane solar air heater.

\section{CONCLUSION}

In this paper the effect of mass flow rate and number of fins on the thermal performance of the simple plate, Rectangular fin as well as Triangular fin plated solar air heater has been investigated theoretically.

The developed mathematical model provides reasonable predictions of the performance of a flat plate, rectangular fin plate and triangular fin solar air heater. 


\section{IJMEIT// Vol.04 Issue 08//August//Page No:1693-1701//ISSN-2348-196x}

The value of the total loss coefficient, collector efficiency factor, collector heat removal factor, temperature rise, Instantaneous efficiency and pressure drop has been obtained from analytical equations for flat plate, rectangular fin plate and triangular fin solar air heater.

The various performance parameters of triangular finned solar air heater have been compared to the corresponding values of rectangular fin plate and triangular fin solar air heater.

Increasing the air flow rate through the solar air heater results not only a higher collector efficiency but also increase in pressure drop.

The use of triangular fins increased the heat transfer surface area as well as the heat transfer coefficient in order to improve the thermal performance of solar air heater.

It has been found that the triangular finned absorber solar air heater gives higher values of thermal efficiency and effective temperature rise in comparison to corresponding flat plate collector and rectangular finned collector operating under similar conditions. The percentage enhancement of these parameters has been found to be $72.55 \%$, $70.74 \%, 67.48 \%$ and $59.56 \%$ at the mass flow rate of $0.05556 \mathrm{Kg} / \mathrm{s}, 0.04167 \mathrm{Kg} / \mathrm{s}, 0.02778 \mathrm{Kg} / \mathrm{s}$ and $0.025 \mathrm{Kg} / \mathrm{s}$ with least fin spacing.

\section{REFERENCE}

1. A. Malhotra, H.P. Garg and A. Palit, "Heat Loss Calculation of Flat Plate Solar Collectors", J. Thermal Energy, 2, 2 (1981).

2. A. Whillier, "Black-painted Solar Air Heaters of Conventional Design", Solar Energy, 8, 31 (1963).

3. Bhandari, D., Singh, S., Performance analysis of flat plate solar air collector with and without fins. Int. J. Eng. Res. Technol. 1 (6), ISSN: 2278-0181, (2012).

4. Chandan Kumar and Hari Singh, "Experimental Analysis of solar air Heater with three different Modification in Absorber Plate", International Journal of
Advanced Tecnology in Engineering and Science, (2014).

5. C.D.Jones and L.F.Smith,"Optimum arrangement of rectangular fins on horizontal surface for free convection heat transfer", Journal of Heat Transfer, Vol. 92, Series C,No.1,pp7-10, (1970).

6. Gupta MK, Kaushik SC. Exergy performance evaluation and parametric studies of solar air heater. Energy; 33:1691-702 (2008).

7. H.C. Hottel and B.B. Woertz, "Performance of Flat Plate Solar Heat Collector", Trans. ASME, 64, 91 (1942).

8. H.P. Garg and G. Dutta, "The Top Loss Calculation for Flat Plate Solar Collectors", Solar Energy, 32, 141 (1984).

9. Karim, M.A., Hawlader, M.N.A., Performance investigation of flat plate, $\mathrm{v}$ corrugated and finned air collectors. Energy 31, 452-470, (2006).

10. S.A. Klein, "Calculation of Flat Plate Collector Loss Coefficients", Solar Energy, 17, 79 (1975).

11. S.B. Thombre and S.P. Sukhatme, "Turbulent Flow Heat Transfer and Friction Factor Characteristic of Shrouded Fin Arrays with Uninterrupted Fins", Experimental Thermal and Fluid Science, 10, 388 (1995). 